\title{
Enhancement of Excess Electron Transfer Efficiency in DNA Containing a Phenothiazine Donor and Multiple Stable Phenanthrenyl Base-pairs
}

\author{
Pascal Roethlisberger $^{[\mathrm{a}]}$, Filip Wojciechowski, ${ }^{[\mathrm{a}, \mathrm{b}]}$ and Christian J. Leumann ${ }^{*[a]}$
}

Electron transport through the $\pi$-stacked DNA base-pairs has attracted considerable interest and continues to be intensively studied. $^{[1]}$ A better understanding of photoinduced negative charge transfer, often called excess electron transfer (EET), could allow to develop DNA nanoscale devices such as biological sensors used in, for example, single-nucleotide polymorphism detection. ${ }^{[2]}$ The electron conducting properties of DNA are determined by the physico-chemical properties of the natural nucleobases and for certain applications, such as DNA nanowires, enhancement of the conducting properties would be highly desirable. One envisioned way to enhance EET efficiency is to replace the natural base-pairs with non-natural hydrogen bonding partners or other aromatic residues with favorable conductive properties. $^{[3]}$

In earlier work we investigated EET through a stacked phenanthrenyl (Phen/Phen) pair in a DNA duplex containing 5(pyren-1-yl)uridine as an electron injector and 5-bromouracil $\left({ }^{\mathrm{Br}} \mathrm{U}\right)$ as an electron acceptor. ${ }^{[3 \mathrm{a}]}$ This provided the first example of electron transfer through a stable, interstrand $\pi$-stacked, aromatic base-pair. However, the reduction potential of Phen is more negative than that of the pyrene donor which excludes electron transfer to occur via a hopping mechanism. This, however, would be necessary to increase efficiency and distance of EET. Indeed, we observed lower efficiency through a Phen/Phen pair compared to an A/T base-pair. To remedy and to explore scope and limitations of EET through such interstrand stacked aromatic residues, devoid of hydrogen-bonding capability, we decided to use a stronger electron donor such as phenothiazine (PTZ; $\mathrm{E}_{\mathrm{ox}}{ }^{*} \approx-2.7 \mathrm{~V}$ vs. SCE, Figure 1$)^{[4]}$ and to use up to three Phen/Phen pairs in between the electron injector and acceptor in

[a] MSc Chem. Pascal Röthlisberger, Dr. Filip Wojciechowski, Prof. Christian J. Leumann

Department of Chemistry and Biochemistry

University of Bern, Freiestrasse 3

CH-3012 Bern (Switzerland)

Fax: (+41)31-631-3422

E-mail: leumann@ioc.unibe.ch

[b] Present address: Department of Chemistry,

University of Konstanz, Universitätsstrasse 10

D-78457 Konstanz (Germany)

Supporting information for this article is available on the WWW under http://www.chemeurj.org/ or from the author. an otherwise similar setup.

PTZ has been used previously as an electron donor in DNA. Using a flexible, acyclic linker PTZ was placed at the $5^{\prime}$-end of DNA or at internal positions facing the natural bases/an abasic site $^{[3 \mathrm{~b}, 5]}$ We reasoned that using a rigid PTZ- $\beta-C$-nucleoside the PTZ unit could intercalate well against an abasic site and stack favorably with a planar Phen-residue, thus enabling efficient EET. On the example of duplexes containing one or three Phen/Phen pairs we show here that EET becomes more efficient as compared to duplexes with the same number of A/T-base-pairs. Moreover, we also demonstrate for the first time that EET can occur over multiple Phen/Phen pairs.

Although a PTZ- $\beta-C$-nucleoside has previously been synthesized by Grinstaff and co-workers, they were unable to protect its $5^{\prime}$ hydroxyl with DMT-Cl, and consequently PTZ was placed at the $5^{\prime}$-end of the DNA. ${ }^{[6]}$ Our attempts at protecting the $5^{\prime}$-hydroxyl with standard DMT-Cl/pyridine also failed. Fortunately, the 5'hydroxyl could be protected with DMT-triflate ${ }^{[7]}$, a reagent occasionally used to protect sterically hindered hydroxyl groups. ${ }^{[8]}$

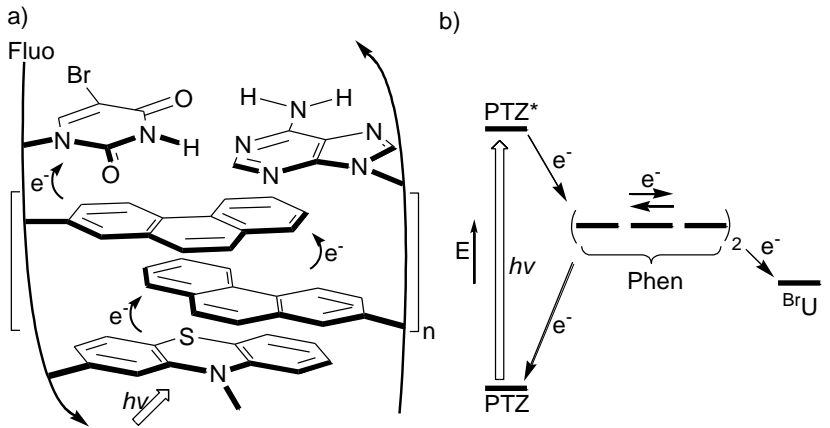

Figure 1. a) A schematic representation highlighting EET from a photoexcited PTZ$\beta$-C-nucleoside (PTZ) placed against an abasic site $(\phi)$, to a interstrand stacked phenanthrenyl (Phen) base-pair and 5-bromouracil $\left({ }^{\mathrm{Br}} \mathrm{U}\right)$; the long arrows represent a phosphodiester backbone b) An EET pathway from photoexcited (PTZ*) to three Phen base-pairs.

The DMT protected nucleoside was subsequently phosphitylated using standard conditions yielding the corresponding phosphoramidite (Scheme S1, SI). PTZ-, Phen-, ${ }^{[9]}$ and 5bromouracil phosphoramidites were used in the synthesis of modified oligodeoxynucleotides (ODNs) 1-14 (Table 1). The ODNs were purified by RP-HPLC and characterized by ESI-MS 
Thermal denaturation experiments were performed with duplexes D1-D9 to judge the stability of DNA containing PTZ and multiple Phen/Phen pairs. The $T_{\mathrm{m}}$ data are summarized in Table 1. PTZ placed against an abasic site (PTZ/ $\phi$, duplex D2) leads to a duplex that is less stable by $5.8{ }^{\circ} \mathrm{C}$ than duplex $\mathbf{D 5}$ containing an A/T base-pair instead. However, PTZ is accommodated much better in sequences containing three Phen/Phen base-pairs; here duplex D4 containing PTZ/ $\phi$ is only $-1.5^{\circ} \mathrm{C}$ less stable than an the duplex $\mathbf{D} 7$ containing an $\mathrm{A} / \mathrm{T}$ basepair. Further evidence that PTZ intercalates and provides stability is obtained by difference of the $T_{\mathrm{m}}$ of duplex D4 (PTZ/ $\left.\phi\right)$ and duplex D8 $(\mathrm{T} / \phi)$ which shows that PTZ stabilizes the duplex by $+3.4{ }^{\circ} \mathrm{C}$ when compared to thymine. In general, insertion of a Phen/Phen pair is consistent with our previously obtained results. ${ }^{[9]}$ One Phen/Phen pair as a replacement for an A/T basepair only slightly destabilizes the duplex $\left(\Delta T_{\mathrm{m}}=-1.0^{\circ} \mathrm{C}, \mathbf{D 1}-\mathbf{D 2}\right)$ and three Phen/Phen pairs (duplex D4) stabilize the duplex by $+3.8^{\circ} \mathrm{C}$ compared to duplex $\mathbf{D 3}$ containing three A/T base-pairs.

Table 1. Sequence and thermal stability $\left(T_{\mathrm{m}}\right)$ data for DNA duplexes $\mathbf{1}-\mathbf{9}^{\mathrm{a}}$

\begin{tabular}{|c|c|c|c|}
\hline No. & $\mathrm{ss}^{\mathrm{b}}$ & Duplex sequence & $\mathrm{T}_{\mathrm{m}} /{ }^{\circ} \mathrm{C}^{\mathrm{a}}$ \\
\hline D1 & $\begin{array}{l}1 \\
2\end{array}$ & $\begin{array}{l}5^{\prime} \text {-GCGAT } \phi(\mathrm{A}){ }_{1} \text { AATGCG-3' } \\
\text { 3'-CGCTAPtz }(\mathrm{T}){ }_{1}{ }^{\mathrm{Br}} \text { UTACGC-Fluo }\end{array}$ & 49.0 \\
\hline D2 & $\begin{array}{l}3 \\
4\end{array}$ & $\begin{array}{l}5^{\prime}-\text { GCGAT } \phi(\text { Phen }){ }_{1} \text { AATGCG-3' } \\
3^{\prime} \text {-CGCTAPtz (Phen) }{ }_{1}{ }^{B \text { CUTACGC-Fluo }}\end{array}$ & 48.0 \\
\hline D3 & $\begin{array}{l}5 \\
6\end{array}$ & 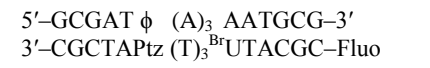 & 51.0 \\
\hline D4 & $\begin{array}{l}7 \\
8\end{array}$ & $\begin{array}{l}5^{\prime}-\text { GCGAT } \phi \quad(\text { Phen })_{3} \text { AATGCG-3' } \\
3^{\prime} \text {-CGCTAPtz }(\text { Phen })_{3}{ }^{B} \text { UTACGC-Fluo }\end{array}$ & 54.8 \\
\hline D5 & $\begin{array}{l}9 \\
10\end{array}$ & 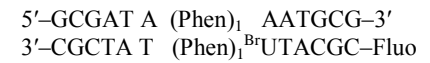 & 53.8 \\
\hline D6 & $\begin{array}{l}3 \\
11\end{array}$ & 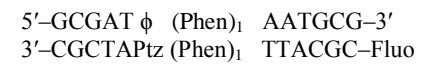 & 49.8 \\
\hline D7 & $\begin{array}{l}12 \\
13\end{array}$ & $\begin{array}{l}5^{\prime} \text {-GCGAT A }(\text { Phen })_{3} \text { AATGCG-3' } \\
3^{\prime} \text {-CGCTA T }(\text { Phen })_{3}{ }^{\text {Br }} \text { UTACGC-Fluo }\end{array}$ & 56.3 \\
\hline D8 & $\begin{array}{l}7 \\
13\end{array}$ & $\begin{array}{ll}5^{\prime}-\text { GCGAT } \phi & (\text { Phen })_{3} \text { AATGCG-3' } \\
3^{\prime}-\text { CGCTA T } & (\text { Phen })_{3}{ }^{\text {Br }} \text { UTACGC-Fluo }\end{array}$ & 51.4 \\
\hline D9 & $\begin{array}{l}7 \\
14\end{array}$ & $\begin{array}{lll}5^{\prime}-\text { GCGAT } \phi & (\text { Phen })_{3} & \text { AATGCG-3' } \\
\text { 3'-CGCTAPtz }(\text { Phen })_{3} & \text { TTACGC-Fluo }\end{array}$ & 57.0 \\
\hline
\end{tabular}

${ }^{\mathrm{a}} \mathrm{c}=1.2 \mu \mathrm{M}$ duplex in $10 \mathrm{mM} \mathrm{NaH}_{2} \mathrm{PO}_{4}, 0.15 \mathrm{M} \mathrm{NaCl}, \mathrm{pH}$ 7.0. Estimated error in $\mathrm{T}_{\mathrm{m}}= \pm 0.5^{\circ} \mathrm{C} .{ }^{\mathrm{b}} \mathrm{ss}$ denotes the single stranded oligonucleotide.

The effect of excess electron transfer in DNAs with $\mathrm{A} / \mathrm{T}$ or Phen/Phen pairs was investigated by selective photoexcitation of PTZ using UV A light $\left(\lambda \max =365 \mathrm{~nm}\right.$, Sylvania $8 \mathrm{~W}$, under $\left.\mathrm{N}_{2}\right)$. In this assay, when migrating electrons encounter and are captured by ${ }^{\mathrm{Br}} \mathrm{U}, \mathrm{Br}^{-}$is released and a uracil-5-yl radical is formed. This radical then abstracts a hydrogen from a 5' adjacent deoxyribose neighbour and after piperidine treatment strand cleavage occurs giving short DNA fragments. ${ }^{[10]}$ We prepared the expected fragments containing a $3^{\prime}$-phosphate $/ 5^{\prime}-$ Fluorescein (Fluo); the tetramer (a, 3'--O4P-ACGC-Fluo) and the pentamer (b, 3'--O4P-TACGC-Fluo) and used them as controls and DNA markers. EET yields are determined by quantifying the formation of fragment a using polyacrylamide gel electrophoresis (PAGE, Figure 2).

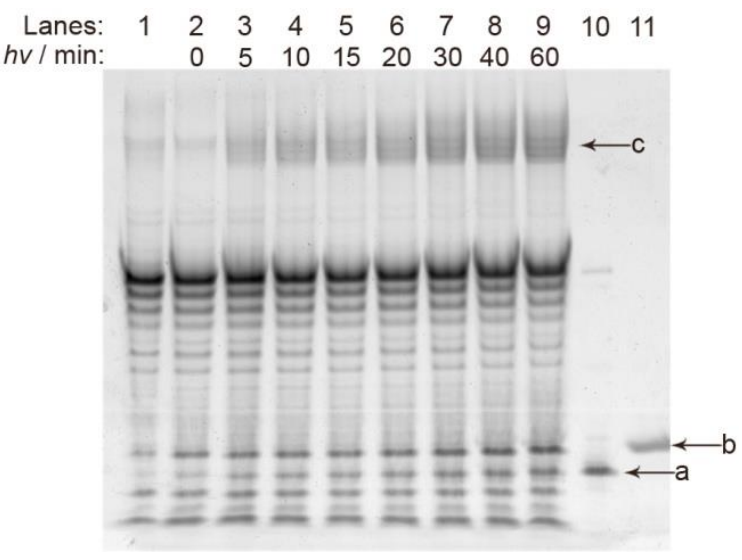

Figure 2. Fluorescence image of a $20 \%$ denaturing PAGE showing DNA strand cleavage of Duplex D4 after UV irradiation ( $365 \mathrm{~nm}$, around $4{ }^{\circ} \mathrm{C}$ ). Conditions; 4.0 $\mu \mathrm{M}$ duplex in $10 \mathrm{mM} \mathrm{NaH} \mathrm{PO}_{4}, 0.15 \mathrm{M} \mathrm{NaCl}, \mathrm{pH}$ 7.0. The DNAs were exposed to UV light for the indicated time and analyzed after subsequent piperidine treatment at $90{ }^{\circ} \mathrm{C}$ for $30 \mathrm{~min}$. Lane 1 contains the control DNA that was treated with piperidine at $90{ }^{\circ} \mathrm{C}$ for 30 min without UV irradiation. Lane 10 contains the synthesized DNA fragment $\mathbf{a}$, and lane 11 contains $\mathbf{b}$.

Selective strand scission was not detected in duplexes D5 and D7 lacking the PTZ electron donor or duplexes D6 and D9 lacking the ${ }^{\mathrm{Br}} \mathrm{U}$. A UV independent cleavage at ${ }^{\mathrm{Br}} \mathrm{U}$ was observed without irradiation after piperidine treatment and is most likely induced by heat. ${ }^{[11]}$ Along with various photoproducts, which do not accumulate with irradiation time, a low mobility band was observed (Figure 2, fragment $\mathbf{c}$ ). The product from this band was isolated from the gel and its mass was determined by $\mathrm{ESI}^{-}$and MALDI mass spectrometry $(\mathrm{m} / \mathrm{z}$ found: 5297.1, see Supporting Information). It could be attributed to a Phen specific intra-strand photoreaction product (Supporting Information, Scheme S2) that accumulated with irradiation time in duplex DNA and single strands containing Phen residues. This product occurs only if ${ }^{\mathrm{Br}} \mathrm{U}$ is present in the sequence and does not accumulate with time to a significant extent, in duplexes D5 or D7 which lack the PTZ donor (see Supporting Information). Since this reaction results from EET, we propose that it occurs most likely by a radical mechanism between uracil-5-yl radical and an adjacent Phen residue, and less likely by way of a cyclobutane adduct ${ }^{[12]}$ (see Supporting Information, Scheme S3 and S4).

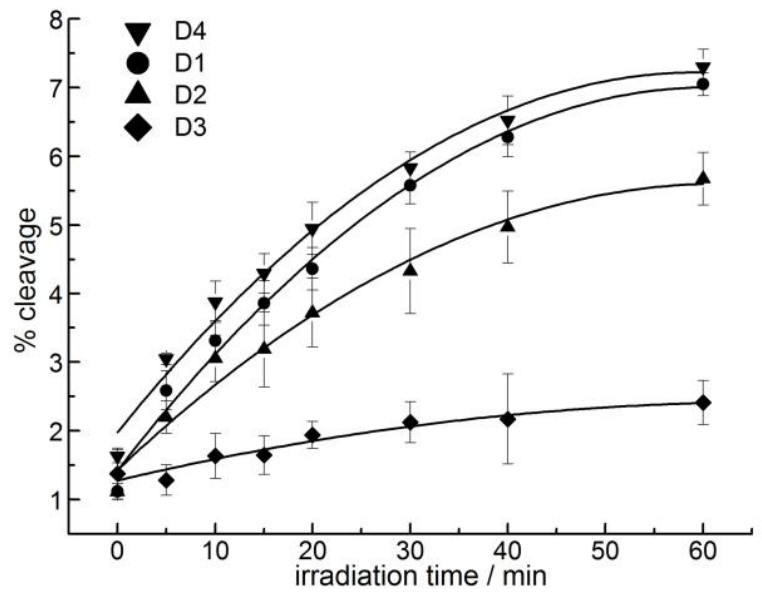

Figure 3. Accumulation of product a, from EET induced DNA strand cleavage, as a function of time. Conditions as for Figure 2. 
Quantifying the amount of formed cleavage product a vs. time for duplexes D1-D4 is shown in Figure 3, and strand cleavage yields after $60 \mathrm{~min}$ of irradiation for duplexes D1-D4, single strands 2, 4, $\mathbf{6}$ and $\mathbf{8}$ is shown in Figure 4. Substituting one A/T base-pair (duplex D1) with a Phen/Phen pair (duplex D2) slightly decreased the yield from $7.0 \%$ to $5.7 \%$. Increasing the number of A/T basepairs (duplex D3) decreased the electron transfer efficiency to 2.4\%. However, replacing three $\mathrm{A} / \mathrm{T}$ base-pairs with three Phen/Phen pairs (duplex D4) increased the electron transfer efficiency to $7.3 \%$. To test if migrating electrons remain within the DNA $\pi$-stack, duplex D4 was saturated with $\mathrm{N}_{2} \mathrm{O}$. ${ }^{[10 \mathrm{~d}, 13]}$ Irradiation under a $\mathrm{N}_{2} \mathrm{O}$ atmosphere maintained a similar cleavage yield (see Supporting Information), providing evidence that strand cleavage did not occur from solvated electrons present in solution but was due to EET within the DNA $\pi$-stack. Single strand 2 (3.4\%) and single strand $6(1.2 \%)$ containing A/T base-pairs exhibited approximately a $50 \%$ decrease in electron transfer efficiency when compared to the duplex DNAs, Figure 3. Phen/Phen containing single strands also exhibited a decrease in EET efficiency. However, single strand 4 (4.1\%) containing one Phen residue was only 28\% less efficient than duplex D2 (5.7\%) containing a Phen/Phen pair. While single strand 8 (2.7\%) containing three Phen residues was $63 \%$ less efficient than duplex D4 $(7.3 \%)$ containing three Phen/Phen pairs.

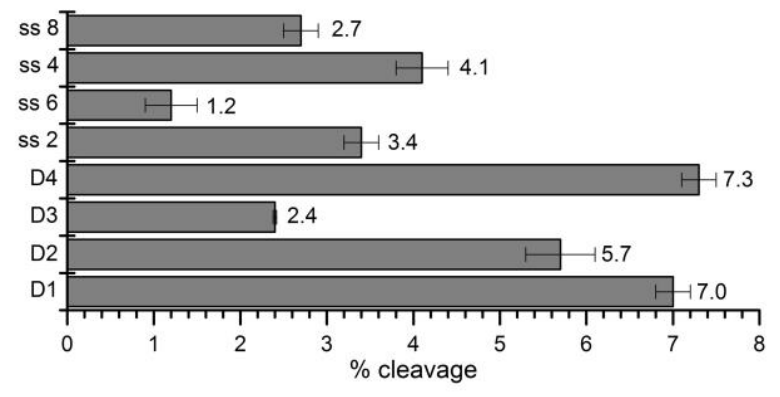

Figure 4. DNA cleavage yields for duplexes D1-D4 and single strands (ss) 2, 4, 6, and 8 after 60 min of UV irradiation.

Both the reduction potentials of Phen $(-2.62 \mathrm{~V} \text { vs. NHE })^{[14]}$ and thymine $(-2.1 \mathrm{~V} \text { vs. SCE })^{[15]}$ are high enough to accept an electron from photoexcited PTZ. Assuming that electron transfer from PTZ to thymine or Phen is an exergonic process, as shown in Figure $1 \mathrm{~b}$ ), and based on the above mentioned reduction potentials, electron transfer should occur more efficiently to thymine than to Phen. This was observed in duplex DNAs D1 and D2. However, in duplex D3 containing three A/T base-pairs we observed a decrease in EET efficiency by increasing the distance from one $\mathrm{A} / \mathrm{T}(3.4 \AA)$ to three A/T base-pairs $(10.2 \AA) .{ }^{[10 \mathrm{~d}, 16]} \mathrm{On}$ the other hand, three Phen/Phen pairs (D2) mediate efficient electron transfer over a distance that is supposed to be twice as long (20.4 ̊). This increase in distance is based on interstrand intercalated Phen residues, a structural model derived from biphenyl containing DNA. ${ }^{[17]}$ This model may also apply here, although there exists no rigorous experimental proof for it. Although the exact reasons for this efficient EET is not evident from our studies, we can speculate that the six phenanthrenes present in duplex D4 are interacting/ $\pi$-stacking in a way that produces favorable LUMO overlap. Asymmetry in the overlap of the HOMOs of the DNA bases has been proposed as an explanation for hole transfer preference in the $5^{\prime}-3^{\prime}$ direction. ${ }^{[18]}$ By analogy, LUMO orbital overlap has also been used to rationalize EET transfer efficiencies. ${ }^{[10 e, 19]}$ Less favorable LUMO overlap in single strands could explain why three intrastrand stacked Phen residues are $63 \%$ less efficient in EET than duplex D4 containing three interstrand stacked Phen/Phen pairs.

From these experiments we conclude that EET readily occurs through DNA duplexes containing up to three Phen/Phen pairs with an efficiency that is superior to duplexes containing three $\mathrm{A} / \mathrm{T}$ base-pairs instead, despite of the fact that the distance between injector and acceptor is larger in the former case. We hypothesize that the reduction potential of PTZ is high enough to reduce a Phen unit, permitting EET via a hopping mechanism, much in the same way as it occurs through long stretches of AT base-pairs. We have shown previously that the Phen units can be peripherally modified with electron donating or accepting groups without compromising with the interstrand intercalation recognition motif. ${ }^{[9]}$ This enables in the future to install a LUMO gradient within the stack of Phen units in a DNA duplex that may suppress back electron transfer. ${ }^{[20]}$ This may render EET over longer distances even more efficient. Moreover, such DNA assemblies could essentially be based also on other aromatic units with favorable electronic conducting properties.

\section{Experimental Section}

See Supporting Information.

\section{Acknowledgements ((optional))}

Financial Support by the Swiss National Science Foundation (grant-No.:200020130373), and the EU for a Marie-Curie Fellowship (F.W) is gratefully acknowledged.

Keywords: DNA recognition• Electron transfer• phenanthrene $\bullet$ oligonucleotides $\bullet$ stacking interactions

[1] a) H. A. Wagenknecht, Nat. Prod. Rep. 2006, 23, 973-1006; b) J. C. Genereux, J. K. Barton, Chem. Rev. 2010, 110, 1642-1662.

[2] a) A. K. Boal, J. K. Barton, Bioconjugate Chemistry 2005, 16, 312-321; b) T. Ito, A. Hayashi, A. Kondo, T. Uchida, K. Tanabe, H. Yamada, S.-i. Nishimoto, Org. Lett. 2009, 11, 927-930.

[3] a) N. A. Grigorenko, C. J. Leumann, Chem. Commun. 2008, 5417-5419; b) T. Ito, Y. Hamaguchi, K. Tanabe, H. Yamada, S.-i. Nishimoto, Angew. Chem. Int. Ed. 2012, 51, 7558-7561; c) M. Tanaka, K. Oguma, Y. Saito, I. Saito, Chem. Commun. 2012, 48, 9394-9396.

[4] T. Ito, A. Kondo, S. Terada, S.-i. Nishimoto, J. Am. Chem. Soc. 2006, 128, 10934-10942.

[5] a) C. Wagner, H. A. Wagenknecht, Org. Biomol. Chem. 2008, 6, 48-50; b) T. Ito, A. Kondo, T. Kamashita, K. Tanabe, H. Yamada, S. Nishimoto, Org. Biomol. Chem. 2009, 7, 2077-2081.

[6] S. A. Hashmi, X. Hu, C. E. Immoos, S. J. Lee, M. W. Grinstaff, Org. Lett. 2002, 4, 4571-4574

[7] J. T. Lundquist, A. D. Satterfield, J. C. Pelletier, Org. Lett. 2006, 8, 3915 3918.

[8] M. Tarköy, M. Bolli, C. Leumann, Helv. Chim. Acta 1994, 77, 716-744.

[9] N. A. Grigorenko, C. J. Leumann, Chem. Eur. J. 2009, 15, 639-645.

[10] a) H. Sugiyama, Y. Tsutsumi, I. Saito, J. Am. Chem. Soc. 1990, 112, 67206721; b) H. Sugiyama, Y. Tsutsumi, K. Fujimoto, I. Saito, J. Am. Chem. Soc. 1993, 115, 4443-4448; c) G. P. Cook, M. M. Greenberg, J. Am. Chem. Soc. 1996, 118, 10025-10030; d) T. Ito, S. E. Rokita, J. Am. Chem. Soc. 2003, 125 11480-11481; e) T. Ito, S. E. Rokita, Angew. Chem. Int. Ed. 2004, 43, 18391842; f) R. Tashiro, A. Ohtsuki, H. Sugiyama, J. Am. Chem. Soc. 2010, 132, 14361-14363.

[11] G. W. Grigg, Nucleic Acids Res. 1977, 4, 969-987. 
[12] a) K. Ohkura, S. Uchiyama, M. Sato, J. M. Diakur, K. Seki, Heterocycles 2003, 59, 459-464; b) J. Lepczynska, K. Komodzinski, J. Milecki, R. Kierzek, Z. Gdaniec, S. Franzen, B. Skalski, J. Org. Chem. 2012, 77, 11362-11367.

[13] S. Breeger, M. von Meltzer, U. Hennecke, T. Carell, Chem. Eur. J. 2006, 12, 6469-6477.

[14] C. Koper, M. Sarobe, L. W. Jenneskens, Phys. Chem. Chem. Phys. 2004, 6, 319-327.

[15] M. P. Scannell, D. J. Fenick, S. R. Yeh, D. E. Falvey, J. Am. Chem. Soc. 1997, 119, 1971-1977.

[16] H.-A. Wagenknecht, Angew. Chem. Int. Ed. 2003, 42, 2454-2460.

[17] Z. Johar, A. Zahn, C. J. Leumann, B. Jaun, Chem. Eur. J. 2008, 14, 10801086 .
[18] M. A. O'Neill, J. K. Barton, Proc. Natl. Acad. Sci. U. S. A. 2002, 99, 16543 16550 .

[19] M. Tanaka, B. Elias, J. K. Barton, J. Org. Chem. 2010, 75, 2423-2428.

[20] F. D. Lewis, X. Liu, S. E. Miller, R. T. Hayes, M. R. Wasielewski, J. Am. Chem. Soc. 2002, 124, 11280-11281.

Received: ((will be filled in by the editorial staff)) Revised: ((will be filled in by the editorial staff)) Published online: ((will be filled in by the editorial staff)) 
Entry for the Table of Contents (Please choose one layout only)

\section{Layout 1:}

Catch Phrase -_______-

Author(s), Corresponding

Author $(s)^{*}$............. Page - Page

Enhancement of Excess Electron

Transfer Efficiency in DNA

Containing a Phenothiazine

Donor and Multiple Stable

Phenanthrenyl Base-pairs
Excess electron transfer (EET) was observed within a DNA duplex containing pi-stacked phenothiazine as an electron donor, phenanthrenes as electron carriers and 5-bromouracil as an electron trap. Increasing the number of pehanthrenyl base-pairs increased EET efficiency. 